\title{
Effects of land use changes on soil erosion in a fast developing area
}

\author{
L. Li $\cdot$ Y. Wang $\cdot$ C. Liu
}

Received: 28 September 2012/Revised: 13 March 2013/Accepted: 22 May 2013/Published online: 12 June 2013

(C) Islamic Azad University (IAU) 2013

\begin{abstract}
Land use changes extensively affect soil erosion, which is a great environmental concern. To evaluate the effect of land use change on soil erosion in fast economic developing areas, we studied land use changes of Guangdong, China, from 2002 to 2009 using remote sensing and estimated soil erosion using the Universal Soil Loss Equation. We calculated the areas and percentage of each land use type under different erosion intensity and analyzed soil erosion changes caused by transitions of land use types. In addition, the impact of land use change on soil erosion in different river catchments was studied. Our results show that forest and wasteland land conversions induce substantial soil erosion, while transition from wasteland to forest retards soil loss. This suggests that vegetation cover changes significantly influence soil erosion. Any conversion to wasteland causes soil erosion, whereas expansion of forests and orchards mitigates it. The most significant increase in soil erosion from 2002 to 2009 was found in the Beijiang catchment corresponding to the transition from forest/orchard to built-up and wasteland. Soil erosion in the Xijiang catchment accelerated in this period due to the enormous reduction in orchard land. In
\end{abstract}

\footnotetext{
L. Li · Y. Wang ( $\square)$

State Key Laboratory of Organic Geochemistry, Guangzhou Institute of Geochemistry, Chinese Academy of Sciences, Guangzhou 510640, China

e-mail: wangyp@gig.ac.cn

L. $\mathrm{Li}$

Graduate University of Chinese Academy of Sciences, Beijing 100049, China

C. Liu

Hunan Technical College of Water Resources and Hydro Power, Changsha 410131, China
}

Hanjiang catchment, erosion was alleviated and vegetation coverage greatly expanded owing to considerable transitions from wasteland and cropland to orchards. Field investigations validated our estimations and proved the applicability of this method. Measures including protecting vegetation, strict control of mining as well as reasonable urban planning should be taken to prevent successive soil erosion.

Keywords Economic development - Land-cover conversion - River catchments · Soil loss - Universal Soil Loss Equation

\section{Introduction}

Land utilization is a socioeconomic behavior in which human beings exploit land to meet their socioeconomic development needs (IGBP-IHDP 1995). Land use change directly affects ecological landscape functions with farreaching consequences for regional biodiversity and soil conservation (Hansen et al. 2004; Stoate et al. 2001). In recent years, the mutual impact of land use/cover change (LUCC) and soil erosion has become a major environmental concern, and strong influences of land use changes on soil erosion and sediment discharges have been identified (Helena et al. 2001; Meng et al. 2001; Rey 2003; Bini et al. 2006; Erda et al. 2006; Solaimani et al. 2009). Land use changes, especially physical expansion of urban areas and extensive use of land for agricultural purposes, may have positive (Fullen et al. 2005) or negative (Souchere et al. 2003) influence on soil erosion because of climatic, environmental and economic conditions. Studies have been carried out to evaluate the effects of LUCC on soil erosion at different spatiotemporal scales (Jordan et al. 2005; 
Szilassi et al. 2006; Ito 2007; Martha et al. 2008; Sharma et al. 2011). In China, many studies of land use impacts on soil erosion were carried out in different regions (Chen 2000; Wang et al. 2001; Zou et al. 2002; Li et al. 2004), and most of them focused on the Loess Plateau of NW China (Yu 1996; Fu et al. 1999). However, few studies have been conducted in the developed area in SE China (Zhu et al. 2003; Liu 2008; Pan et al. 2010; Ma et al. 2010).

As the most developed province in China, Guangdong experienced rapid economic growth, fast population increase and massive construction and urban sprawl in the past three decades. The character of land use experienced drastic changes causing distinct soil erosion, which makes Guangdong a good site to examine effects of LUCC on soil erosion. This paper presents a case study on the impact of land use and land use change on soil erosion in Guangdong Province from 2002 to 2009 using remote sensing and GIS techniques. The LUCC effects were analyzed on the scale of catchments, aiming to provide information for effective soil erosion prevention and water conservation planning.

\section{Materials and methods}

Study area and data

Guangdong Province is located in the southernmost part of China. It lies between $109^{\circ} 45^{\prime}$ and $117^{\circ} 20^{\prime} \mathrm{E}$ longitude and $20^{\circ} 09^{\prime}$ and $25^{\circ} 31^{\prime} \mathrm{N}$ latitude, covering an area of approximately $179,800 \mathrm{~km}^{2}$, about half the size of Germany and comparable to Japan, accounting for about $2 \%$ of China's land area. It consists of highlands in the eastern, western and northern borders hills and terraces in the middle and plains in the south. The river system in Guangdong is extensively developed with up to 2000 rivers and streams densely scattered in it (Fig. 1). Guangdong enjoys a humid subtropical climate with abundant precipitation. The annual average temperature is between 18 and $24{ }^{\circ} \mathrm{C}$, and the annual average rainfall reaches $1,700 \mathrm{~mm}$. Winters are short, mild and relatively dry, while summers are long, hot and very wet. The exposed rocks in Guangdong are mainly granite, arenaceous shale, metamorphic rocks, limestone and red shale, which is widely distributed in the middle and

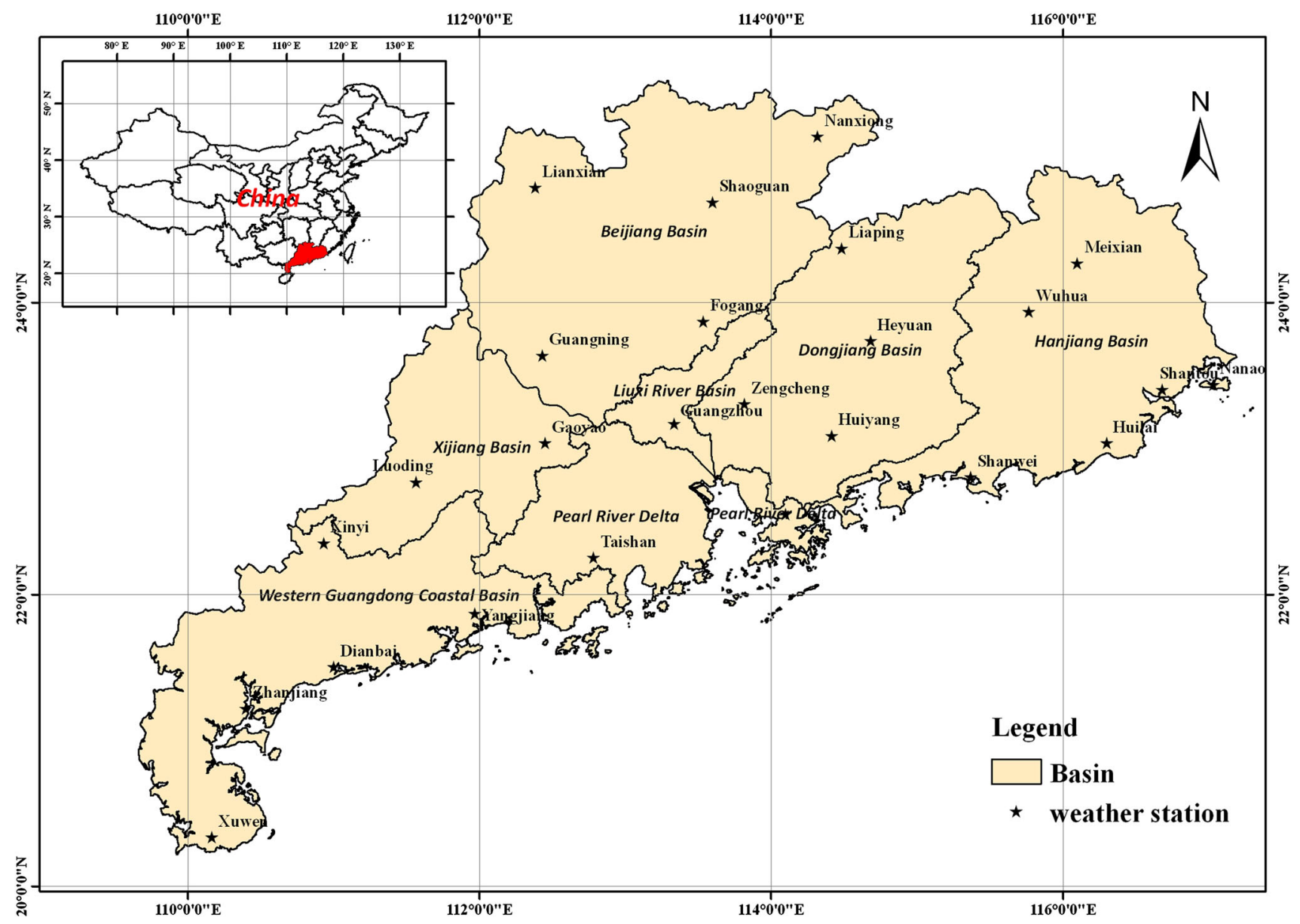

Fig. 1 The study area map showing seven basins and 25 weather stations (in black star) in the Guangdong province 
low mountain areas. These rocks are easily eroded and weathered under the hot and rainy conditions. The relatively frequent tectonic movement in recent geologic ages promotes the deep weathering to soils which might cause soil erosion (Shi 1991). However, the high vegetation coverage in this area prevents soil from eroding to some extents.

The data for land use mapping in this study mainly include MODIS 500-m satellite images (L1B) and MODIS products of vegetation indices acquired in early October in 2002 and 2009. The Guangdong's pedological map with a scale of $1: 1,000,000$ is a government issued atlas (Guangdong soil census office 1993); digital elevation model (DEM) data are from the NASA's 90-m Shuttle Radar Topography Mission data; Monthly rainfall data from 2000 to 2009 of the study area are downloaded from the China Meteorological Data Sharing Service System (http://cdc.cma.gov.cn/).

\section{Methodology}

\section{Land use classification}

MODIS L1B cloud-free image data with a spatial resolution of $500 \mathrm{~m}$ collected early October, in both 2002 and 2009 , were used for land use classification. A systematical geometric correction and radiometric correction were applied to the images using the calibration parameter file (CPF) released by the United States Geological Survey Earth Resources Observation Systems Data Center. The MODIS images were co-registered with 50 ground control points. The geometric accuracy of the registration was estimated to be less than 0.5 pixels.

To obtain accurate land use maps of the study area, we used a combination of supervised classification with a decision tree approach. Firstly, guided by images with higher spatial resolution such as Landsat TM, SPOT and Google Earth maps, several training areas were selected. Next, a support vector machine was used to classify the satellite images into four types: water, vegetation, built-up land and wasteland. Finally, based on a set of rules on attributes such as DEM and EVI (Enhanced Vegetation Index), which were determined based on prior knowledge and existing data, we built a decision tree classifier to further divide vegetation into forest, orchard and cropland. The final land use map distinguishes six categories: water, wasteland, built-up land, forest, orchard and cropland. The wasteland actually includes waste grassland, saline-alkaline land, bare and undeveloped land. The accuracy of classification was evaluated using the $30-\mathrm{m}$ resolution TM images covering the study areas. MODIS Land Cover Type products by IGBP classification scheme were also used.
Over 50 samples for each class were selected to calculate Kappa coefficient.

\section{Extraction of hydrologic information}

The boundaries of each catchment were extracted from the DEM data using the Hydrology toolbox of ESRI's ArcGIS software (version 9.2) including the procedures of Fill, Flow Direction and Flow Accumulation (Tang and Yang 2006). The main river channels in Guangdong Province were also derived from the grid DEM data forming the drainage map. Seven catchments were extracted according to the drainage map of Guangdong, which are Dongjiang Basin, Xijiang Basin, Beijiang Basin, Pearl River Delta, Liuxi River Basin, Hanjiang Basin and western Guangdong Coastal Basin, respectively. The boundaries of these basins are shown in Fig. 1 .

\section{Soil erosion estimation}

In this study, the mean annual soil erosion was calculated using the Universal Soil Loss Equation (USLE) because of its operating simplicity, convenient inputting availability and extensive applicability. Generally, USLE is defined as:

$A=R \cdot K \cdot L \cdot S \cdot C \cdot P$

where $A$ is the mean annual soil erosion in $\mathrm{t} /\left(\mathrm{hm}^{2} * \mathrm{a}\right), R$ is rainfall-runoff erosivity factor (MJ mm hm $\mathrm{hm}^{-2} \mathrm{~h}^{-1} \mathrm{a}^{-1}$ ), $K$ is soil erodibility factor $\left(\mathrm{t} \mathrm{h} \mathrm{MJ}^{-1} \mathrm{~mm}^{-1}\right), L$ is slope length factor, $S$ is slope steepness factor, $C$ is cover and management factor, and $P$ is the support practice factor. The definition and method of calculation of each factor are laid out in the following parts.

\section{$R$ factor}

The rainfall-runoff factor reflects the potential effect of variations in climate and precipitation on soil erosion keeping all other factors constant. It is the basis for quantitative studies of soil erosion. We chose the formula suggested by Zhou et al. (1995) which has been proven suitable for southern China:

$R=\sum_{i=1}^{12}(-1.15527+1.792 \mathrm{Pi})$

where $R$ is the rainfall-runoff erosivity factor per year, and $\mathrm{Pi}$ is the monthly rainfall in millimeters. Monthly rainfall data from 2000 to 2009 collected from over 50 weather stations in Guangdong were used to calculate the mean $R$ value of each station. The mean regional $R$ was then calculated using Kriging interpolation between the geographic coordinates of each station to acquire the spatial distribution of $R$ values which were plotted on a map. 


\section{$K$ factor}

The $K$ factor is an indicator of soil detachment and transport by raindrop impact and surface flow. It accounts for the influence of soil properties on soil loss during storm events in upland areas. The value of $K$ is closely related to soil texture, organic matter content, structure and permeability. Methods of calculating $K$ include the soil erodibility nomograph constructed by Wischmeier et al. (1971) as well as regional methods derived by individual researchers. Since the soil erodibility in Guangdong is similar to that in red soil areas in southern China, we estimated the $K$ factor on the basis of soil type maps of the study area using previously proposed assignments ( $\mathrm{Lv}$ and Shen 1992; Liang and Shi 1999; Zhang 2005).

\section{$L$ and $S$ factor}

The $L$ and $S$ factors, which are functions of slope inclination and slope length, are used to evaluate the effect of topography on erosion. Generally, soil erosion correlates with slope. Two factors, the slope length $(L)$ and the slope steepness $(S)$, are widely used to reflect the influence of the slope gradient on soil erosion. In this study, the slope map was extracted from DEM data by using the terrain features analysis tool in the software of ArcGIS (version 9.2).

We used the $L$ (slope length) factor from McCool et al. (1987):

$L=(\lambda / 22.13)^{m}$

where $\lambda$ is slope length (in meter) (Robert 2000), $m$ is a variable slope length exponent determined by slope steepness. The exponent $\mathrm{m}$ is taken to be 0.2 with a slope angle below $1 \%, 0.3$ with a slope angle below $3 \%, 0.4$ with a slope angle below $5 \%$ and 0.5 when the slope angle is above $5 \%$.

The application of $S$ is limited to slopes below $18 \%$ because it is the upper bound considered in USLE (McCool et al. 1987). We used the USLE equations for slopes below $18 \%$ and the equation proposed by Liu et al. (1994) for steeper ones. Their actual form is stated in Eq. 4.

$S= \begin{cases}10.8 \sin \alpha+0.03 & \alpha<9 \% \\ 16.8 \sin \alpha-0.5 & 9 \% \leq \alpha<18 \% \\ 21.9 \sin \alpha-0.96 & \alpha \geq 18 \%\end{cases}$

where $S$ is the slope steepness factor and $\alpha$ is the slope angle.

\section{C factor}

The $C$ factor is the cropping and management factor, which reflects how a conservation plan affects the erosion rate. It is commonly used to compare the relative impact of different management schemes for conservation. It has been proven that the $C$ factor is closely related to vegetation cover. We calculated Normalized Difference Vegetation Index (NDVI) and used it to produce vegetation cover map for October 2002 and October 2009 with 500-m resolution MODIS data.

Ma et al. (2001) suggest the following relation between $\mathrm{C}$ factor and vegetation cover:

$C= \begin{cases}1 & \left(f_{g}=0\right) \\ 0.6508-0.343 * \lg f_{g} & \left(0<f_{g}<78.3 \%\right) \\ 0 & \left(f_{g} \geq 78.3\right)\end{cases}$

In which $f_{g}$ is defined as (NDVI $\left.-\mathrm{NDVI}_{\min }\right) /\left(\mathrm{NDVI}_{\max }\right.$ $-\mathrm{NDVI}_{\text {min }}$ ), NDVI being the vegetation index of each pixel and $\mathrm{NDVI}_{\text {min }}$ and $\mathrm{NDVI}_{\max }$ are the maximum and minimum value of NDVI in the study area.

\section{$P$ factor}

The erosion control practice factor $P$ is defined as the ratio of soil loss with a specific support practice, such as terrace cropping and contour farming, to the corresponding loss with upslope and downslope tillage. The current estimation of $P$ is always based on land use type. In the absence of onsite experiments, the value of $P$ is generally controlled by vegetation cover and field slope. In this study, $P$ was set according to American Agriculture Handbook Number 703 and related literature (Huang et al. 2004; Chen et al. 2007; Ma et al. 2010). Following these authors, we set $P-0$ for water, 1 for wasteland and built-up area, 0.5 for forested land, 0.2 for orchard land and 0.35 for cropland.

\section{Results and discussion}

Land use changes

Our classification accuracy was estimated about $81.6 \%$ for 2002 and $80.5 \%$ for 2009 with kappa coefficient about 0.79 and 0.776 for 2002 and 2009, respectively. Our resulting 2002 and 2009 land use maps are shown in Fig. 2. The land use change was calculated using the "changing detection" module of RSI's ENVI software. The change matrix of land use categories in Guangdong from 2002 to 2009 is presented in Table 1. It illustrates the dramatic decrease in wasteland and cropland and the equally dramatic increase in built-up acreage and orchards.

Inspection of the change matrix shows that in seven years, wasteland dropped to $6,180 \mathrm{~km}^{2}$ in 2009 from $9,544.25 \mathrm{~km}^{2}$ in 2002 and cropland decreased from $11,791.5$ to $8,867.5 \mathrm{~km}^{2}$. In contrast, construction land and orchard acreage experienced an increase of 3,619.5 and $4,249 \mathrm{~km}^{2}$, respectively. The built-up acreage converted 
Fig. 2 Land use maps of Guangdong in 2002 (above) and 2009 (below). The MODIS image is classified into 6 types: water (in blue color), built-up land (in red color), forest (in dark green color), orchard (in light green color) and cropland (in yellow color)

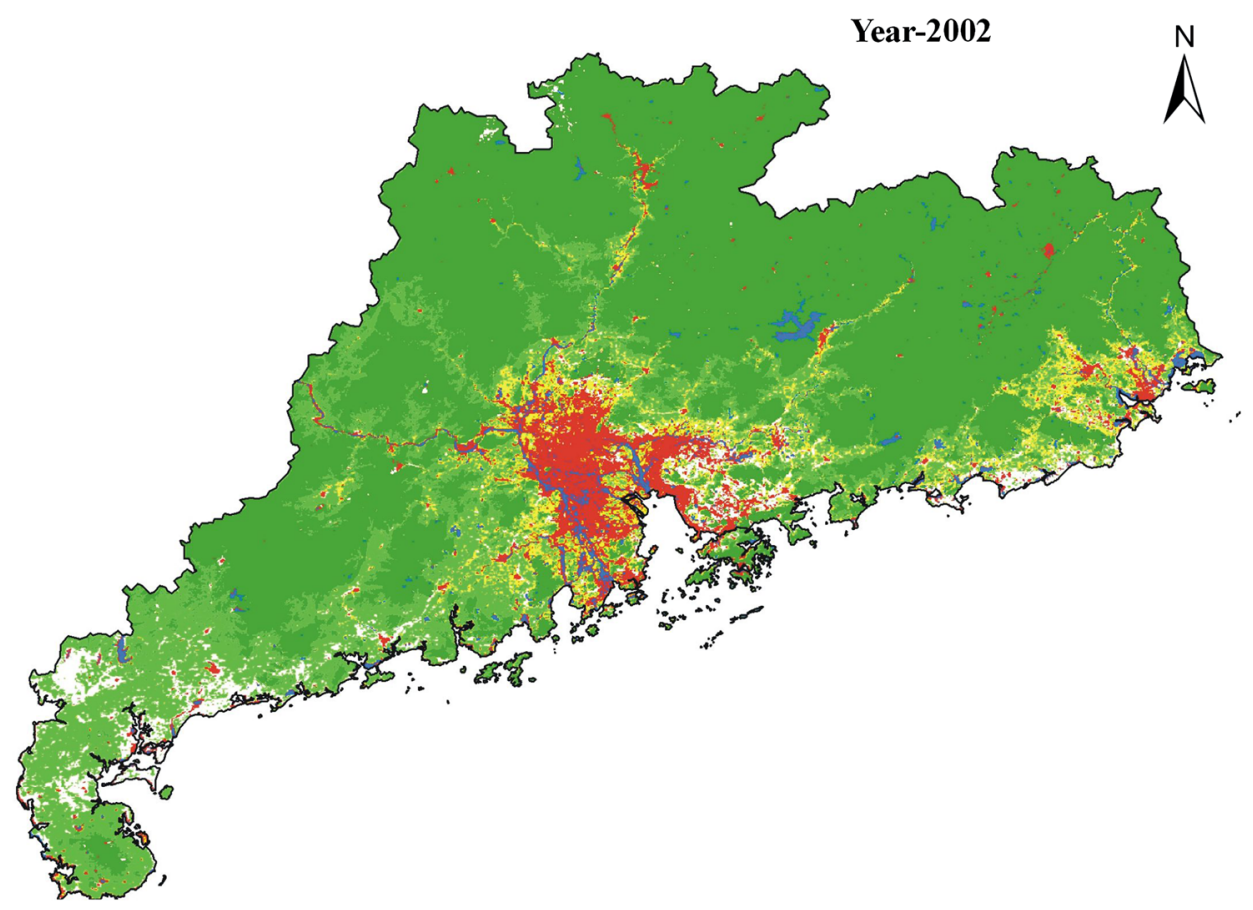

Year-2009

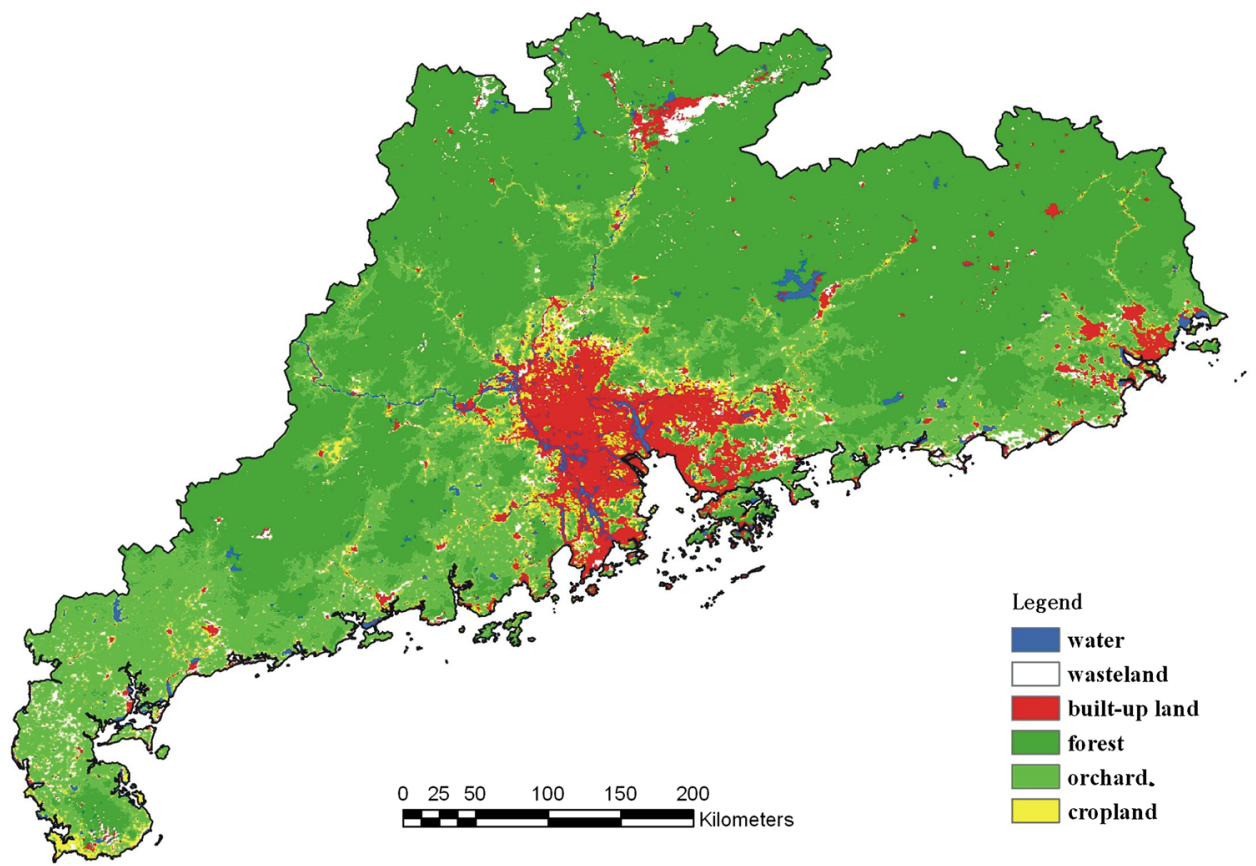

from wasteland and cropland reached 1,969.25 and $1,728.25 \mathrm{~km}^{2}$, while the orchard areas converted from wasteland and cropland were $3,986.25$ and $5,069.75 \mathrm{~km}^{2}$.

The dynamics behind land use change as described above may be explained by some socioeconomic indices of Guangdong collected from Guangdong Statistical Yearbook (Statistics Bureau of Guangdong Province \& National Bureau of Statistics Guangdong Survey Organization 2003 and 2010). Guangdong witnessed marked economic development and population growth since 2002. The gross domestic product (GDP) of secondary industry including industry and construction increased from 6,143.4 million Yuan in 2002 to 19,419.7 million Yuan in 2009, whereas the percentage of primary industry decreased by $2.1 \%$ in the same period. In the meantime, the urban population rose from 27.7 million to 43.6 million. Government statistics show that between 2002 and 2009, Guangdong completed many housing construction projects to settle the 
Table 1 Change matrix of Guangdong's land use of year 2002 and $2009\left(\mathrm{~km}^{2}\right)$

\begin{tabular}{|c|c|c|c|c|c|c|c|}
\hline \multirow[t]{2}{*}{2009} & \multicolumn{7}{|l|}{2002} \\
\hline & Water & Wasteland & Built-up land & Forest & Orchard & Cropland & Total \\
\hline Water & $2,126.5$ & 49.5 & $1,115.25$ & 280.25 & 69.75 & 229.25 & $3,870.5$ \\
\hline Wasteland & 67.75 & $2,283.5$ & 369.75 & $1,580.5$ & 1,066 & 812.5 & 6,180 \\
\hline Built-up land & $1,534.25$ & $1,969.25$ & $9,240.75$ & 857.75 & 345.75 & $1,728.25$ & 15,676 \\
\hline Forest & 345.5 & 320 & 189.5 & $110,799.8$ & $1,667.25$ & 47.75 & $113,369.75$ \\
\hline Orchard & 84.75 & $3,986.25$ & 175.5 & 749.25 & 28,042 & $5,069.75$ & $38,107.5$ \\
\hline Cropland & 456.75 & 935.75 & 966.75 & 103 & $2,657.5$ & $3,850.75$ & $8,970.5$ \\
\hline Total & $4,615.5$ & $9,544.25$ & $12,057.5$ & $114,370.5$ & $33,848.25$ & $11,738.25$ & $186,174.3$ \\
\hline
\end{tabular}

continuously increasing population. The main reason for the fast expansion of orchards was presumably caused by the increasing economic income of the farmers. With a blooming industry, urban expansion and agricultural production decreasing are the main driving forces for land use change.

\section{Soil erosion maps}

The soil loss amounts of both years were calculated by multiplying all the factors in USLE. They were reconfigured to a spatial resolution of $500 \mathrm{~m}$ using Spatial Analyst module in ArcGIS 9.2. The average annual soil erosion amount was estimated to be $10.81 \mathrm{t} /\left(\mathrm{hm}^{2} * \mathrm{a}\right)$ in 2002 versus $21.86 \mathrm{t} /\left(\mathrm{hm}^{2} * \mathrm{a}\right)$ in 2009 , a formidable increase. The soil erosion maps of Guangdong in 2002 and 2009 are shown in Fig. 3. We constructed them after classifying the calculated results in each pixel of $500 \mathrm{~m}$ into six levels in accordance with the soil erosion intensity standard issued by the Ministry of Water Conservation, China. These levels are low erosion for $A<5 \mathrm{t} /\left(\mathrm{hm}^{2} * \mathrm{a}\right)$, mild erosion for $5 \leq A \leq 25 \mathrm{t} /\left(\mathrm{hm}^{2} * \mathrm{a}\right)$, moderate erosion for $25 \leq A \leq 50 \mathrm{t} /$ $\left(\mathrm{hm}^{2} * \mathrm{a}\right)$, serious erosion for $50 \leq A \leq 80 \mathrm{t} /\left(\mathrm{hm}^{2} * \mathrm{a}\right)$, very serious erosion for $80 \leq A \leq 150 \mathrm{t} /\left(\mathrm{hm}^{2 *} \mathrm{a}\right)$ and catastrophic erosion for $A>150 \mathrm{t} /\left(\mathrm{hm}^{2} * \mathrm{a}\right.$ ) (Fig. 3). Inspection of Fig. 2 shows that, soil erosion of Guangdong from 2002 to 2009 is generally mild. However, in some areas, soil erosion reaches moderate to severe levels primarily in the northern and northeastern areas of the province as well as some small scattered hilly areas.

We have collected the area and proportion of each soil erosion level for both years in Table 2. The total areas of low-mild erosion decreased from $91.92 \%$ in 2002 to $87.5 \%$ in 2009 , whereas the percentage of severe soil erosion over the same period increased to $5.46 \%$ from $2.96 \%$. The low erosion acreage showed the largest change decreasing by $10,792 \mathrm{~km}^{2}$ in the seven-year period, while the acreages of the other erosion levels from mild to severe erosion show increasing trends, indicating the soil erosion level in whole province has become worse.
To verify the calculation results, we carried out a field investigation in the most seriously eroded area in northern Guangdong, which is labeled in a red box in Fig. 3(2). Figure 4 shows some field photographs of some severe soil erosion sites in the northern areas of Guangdong, where we found typical soil erosion phenomena such as soil erosion of bare oil along river shores, mud flow formed from severe soil erosion, soil erosion of bare soil in waste land in flatslope areas, mine tails in waste land, steep slope formed by mining and construction engineering, soil collapse, as well as mining-induced deforest and damages to vegetation. Through the field survey, we learned that large areas of reckless mining activities in recent years have led to excessive deforestation and a substantial increase in barren land, thus causing serious soil and water loss. These findings in areas of severe soil erosion evidenced our speculations, supported our estimations of erosion magnitude and proved the applicability of this method.

The land use changes and soil erosion change

We analyzed the changes in soil erosion and land use from 2002 to 2009 to explore the relationship between the soil erosion and land use induced by human activities. Overlaying the spatial distribution of soil erosion intensity and land use types for both years, we calculated the areas of different erosion intensity for each land use type (Table 3). Table 3 shows that from 2002 to 2009, areas at different soil erosion levels changed as the areas of the land use changes. Wasteland and cropland show obvious decreasing at all erosion levels due to the extensive decreasing in land use areas. The erosion level of the forest land obviously changed from low erosion level to serious and severe erosion levels, while the areas of forest kept steady. Orchard shows similar trend to forest, but it caused more soil erosion due to its areas have increased obviously in this period. The area increasing is mainly at low erosion level for built-up land, so although built-up area increased $3,618.5 \mathrm{~km}^{2}$ in this period, it caused slight increasing in soil erosion. 
Fig. 3 Soil erosion maps of Guangdong in 2002 (above) and 2009 (below)

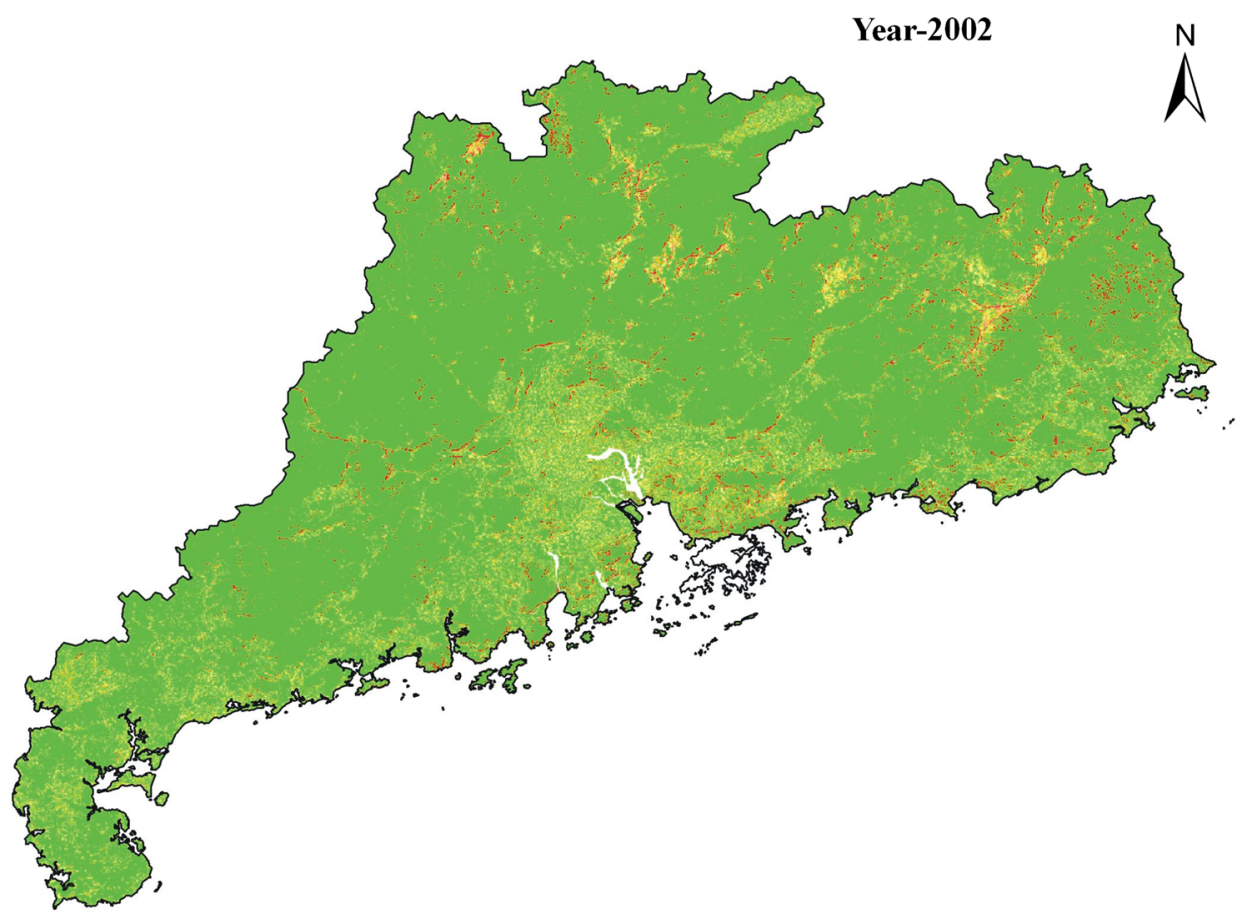

Year-2009

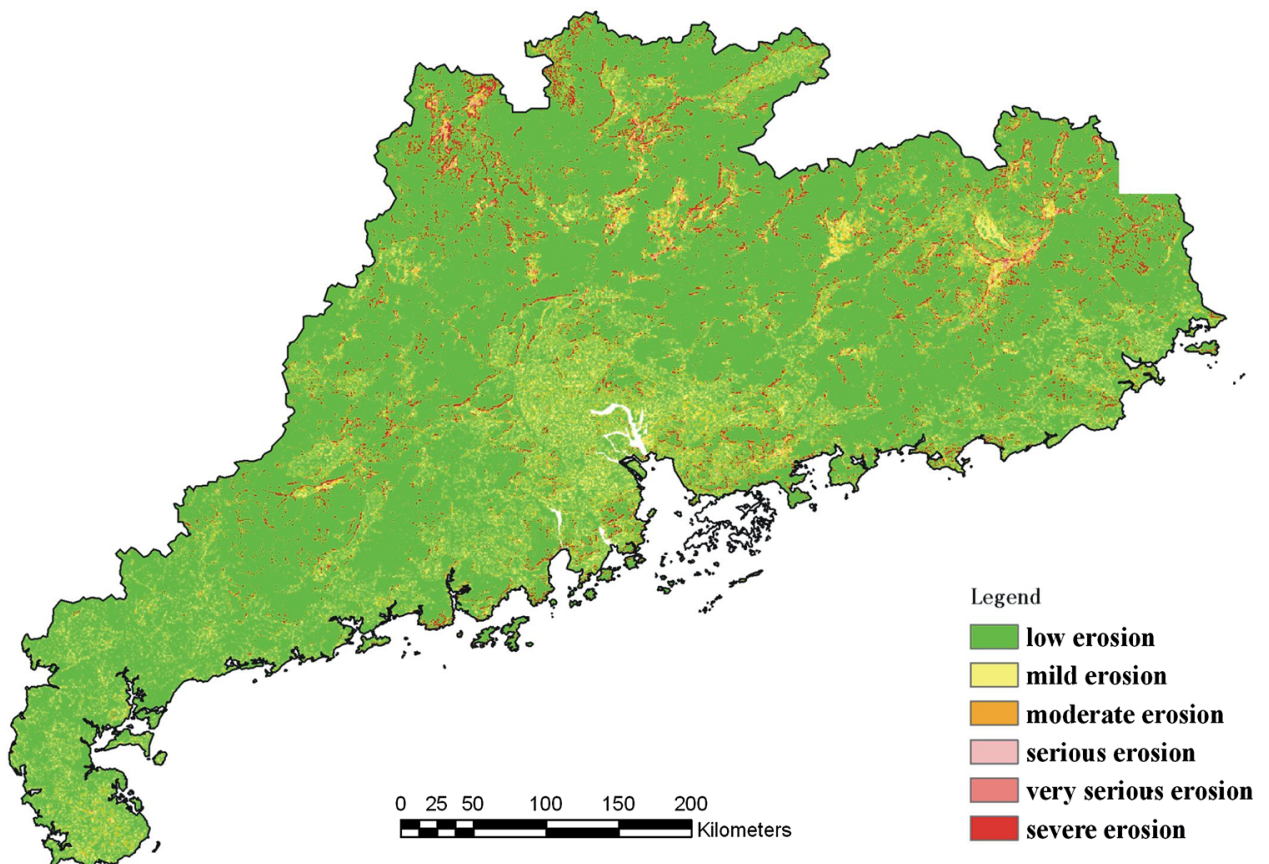

The above analysis can be also validated by calculating the average annual soil erosion amount of different land use categories. To further discuss how land use changes affect the soil erosion, overlay analysis for different land use types and the slope map was performed to calculate the mean slope angle of each land use type in 2002 and 2009 (Chen and Huang 2012).

The most pronounced change in soil erosion occurred in wasteland, with a mean annual soil erosion amount reaching $60.19 \mathrm{t} /\left(\mathrm{hm}^{2} * \mathrm{a}\right)$ in 2009 from $18.43 \mathrm{t} /\left(\mathrm{hm}^{2 * a}\right)$ in 2002. These values indicate wasteland erosion is the most serious issue in need of comprehensive management. Its dramatic rise might be attributed to forest overexploitation on steep mountainous slopes, for the mean slope of wasteland increased from $1.31^{\circ}$ in 2002 to $1.87^{\circ}$ in 2009 . The other reasons might be the increased utilization of low erodible soil and the abandonment of high erodible soil, such as land reclamation leading to a decrease in wetlands 
Table 2 The areas and percentage of different soil erosion levels in 2002 and 2009

\begin{tabular}{|c|c|c|c|c|c|}
\hline \multirow[t]{2}{*}{ Erosion levels } & \multicolumn{2}{|l|}{2002} & \multicolumn{2}{|l|}{2009} & \multirow[t]{2}{*}{ Change area $\left(\mathrm{Km}^{2}\right)$} \\
\hline & Erosion area $\left(\mathrm{Km}^{2}\right)$ & Percentage $(\%)$ & Erosion area $\left(\mathrm{Km}^{2}\right)$ & Percentage $(\%)$ & \\
\hline Low erosion & $157,542.3$ & 85.89 & $146,750.3$ & 80.01 & $-10,792$ \\
\hline Mild erosion & $11,068.75$ & 6.03 & $13,785.25$ & 7.52 & $2,716.5$ \\
\hline Moderate erosion & 4,422 & 2.41 & $5,516.5$ & 3.01 & $1,094.5$ \\
\hline Serious erosion & $2,388.75$ & 1.30 & $3,372.5$ & 1.84 & 983.75 \\
\hline Very serious erosion & $2,561.25$ & 1.39 & $3,971.25$ & 2.17 & 1,410 \\
\hline Severe erosion & $5,431.25$ & 2.96 & $10,018.5$ & 5.46 & $4,587.25$ \\
\hline
\end{tabular}

Fig. 4 Field photographs of some severe soil erosion sites in the northern areas of Guangdong (a soil erosion of bare soil along river shores; b and $\mathbf{c}$ mud flow formed from severe soil erosion; $\mathbf{d}$ soil erosion of bare soil in waste land with flat slopes; e mine tails in waste land; f mininginduced deforest and damages to vegetation; $\mathbf{g}$ steep slope formed by mining and construction engineering. $\mathbf{h}$ Soil collapse)
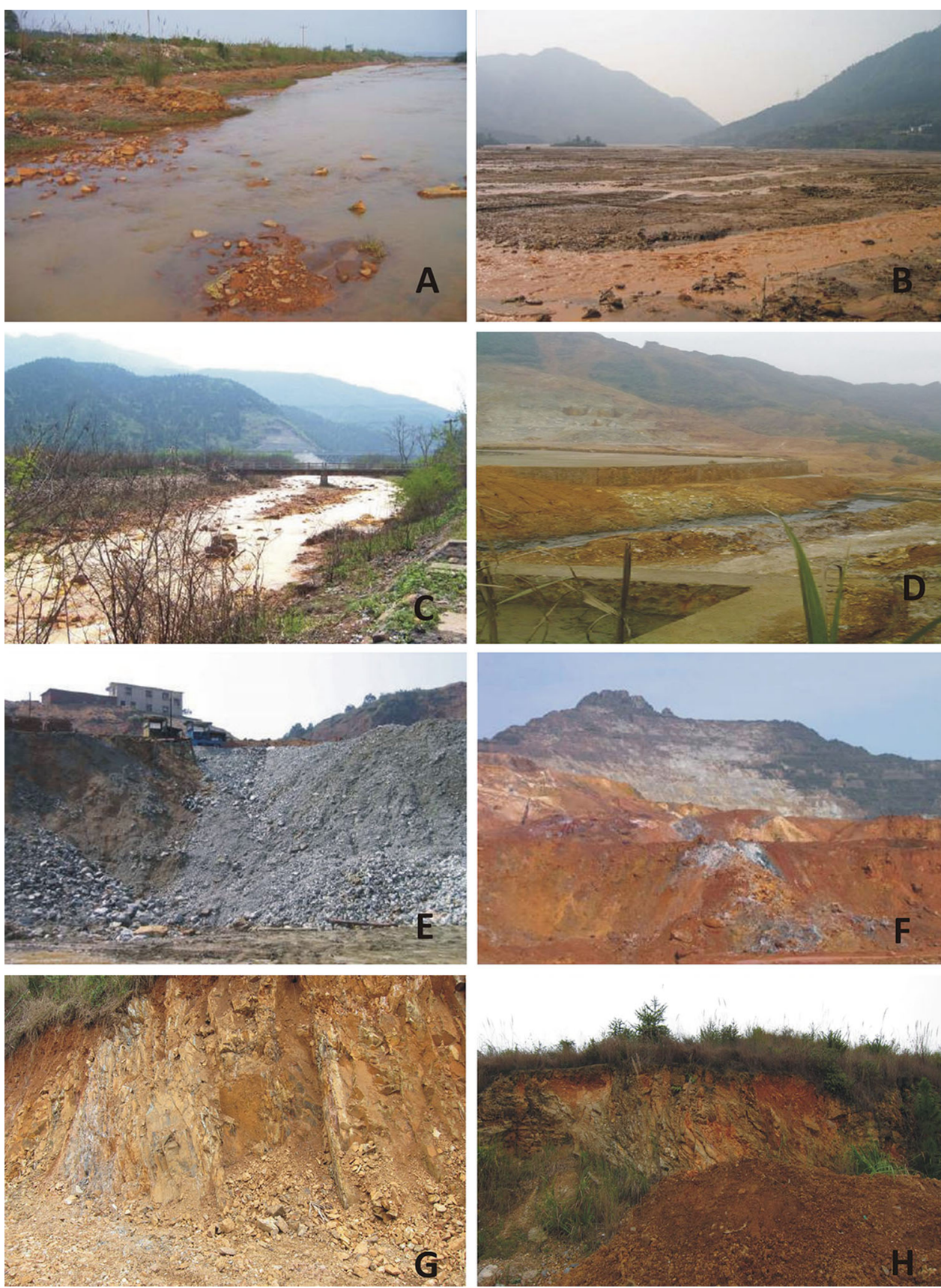
Table 3 Areas of different soil erosion intensity for every land use type $\left(\mathrm{km}^{2}\right)$

\begin{tabular}{|c|c|c|c|c|c|c|c|c|c|c|}
\hline \multirow[t]{2}{*}{ Erosion levels } & \multicolumn{2}{|c|}{ Wasteland } & \multicolumn{2}{|c|}{ Built-up land } & \multicolumn{2}{|l|}{ Forest } & \multicolumn{2}{|l|}{ Orchard } & \multicolumn{2}{|c|}{ Cropland } \\
\hline & 2002 & 2009 & 2002 & 2009 & 2002 & 2009 & 2002 & 2009 & 2002 & 2009 \\
\hline Low erosion & $5,800.5$ & $3,160.25$ & $6,356.75$ & $9,021.75$ & $103,860.25$ & $87,197.5$ & $29,189.5$ & 27,585 & $8,323.5$ & $5,362.75$ \\
\hline Mild erosion & $1,682.5$ & 765 & $2,688.75$ & $2,723.5$ & $1,822.5$ & $3,216.25$ & 2,942 & $4,099.5$ & 1,645 & $1,248.25$ \\
\hline Moderate erosion & 866.75 & 316.5 & 888 & 628.25 & $1,422.25$ & $2,056.75$ & 628.75 & 974 & 478 & 372.25 \\
\hline Serious erosion & 379.75 & 164.5 & 401 & 292.25 & $1,015.5$ & 1,479 & 284.75 & 475 & 260.5 & 189.75 \\
\hline Very serious erosion & 269.25 & 173 & 315.25 & 250.25 & $1,434.5$ & 1,972 & 232.75 & 441.5 & 264.5 & 200.25 \\
\hline Severe erosion & 365 & 313.75 & 423 & 343.25 & $3,951.75$ & $5,896.25$ & 245.25 & 630.5 & 399.75 & 331.75 \\
\hline
\end{tabular}

as well as the expansion of saline-alkaline soil and sand. Cropland turned out to be subjected to the second heaviest erosion with the mean annual soil erosion amount growing to $28.78 \mathrm{t} /\left(\mathrm{hm}^{2} * \mathrm{a}\right)$ in 2009 from $10.42 \mathrm{t} /\left(\mathrm{hm}^{2} * \mathrm{a}\right)$ in 2002 . This increase was presumably caused by the cultivation and encroachment of sloping terraces in hilly regions, for the slope of cropland in 2009 increased by $0.2^{\circ}$ compared to that in 2002. In addition, forested areas experienced an increase in about $14 \mathrm{t} /\left(\mathrm{hm}^{2} * \mathrm{a}\right)$ in soil erosion. It is likely caused by forest exploitation as it is the largest land use type in Guangdong. In general, forest with a canopy density less than 0.9 shows a less degree of soil erosion (Chen et al. 2007). The destruction of forest by human activities affects the ability of soil consolidation and vegetation cover. The mean annual soil erosion potential of construction land remained high, with the average annual soil erosion amount of $23.63 \mathrm{t} /\left(\mathrm{hm}^{2} * \mathrm{a}\right)$ in 2002 and $26.75 \mathrm{t} /$ $\left(\mathrm{hm}^{2} * \mathrm{a}\right)$ in 2009 , owing to soil and water destructions caused by frequent human activities in the region.

Superposition of land use transition maps and soil erosion maps reveals the quantitative relationship between the dynamics of land use change and soil erosion. The results are shown in Table 4. The largest increase in soil erosion occurred there where forestland was converted to built-up land, a number as high as $107.64 \mathrm{t} /\left(\mathrm{hm}^{2} * \mathrm{a}\right)$. The second most detrimental land use transition was from forest to wasteland, with an increase in average annual soil erosion amount of $81.56 \mathrm{t} /\left(\mathrm{hm}^{2} * \mathrm{a}\right)$. From most to least severe land

Table 4 Change in annual erosion corresponding to land use conversion matrix $\left(\mathrm{t} /\left(\mathrm{hm}^{2} * \mathrm{a}\right)\right)$

\begin{tabular}{lccccc}
\hline 2002 & \multicolumn{6}{l}{2009} & & & & \\
\cline { 2 - 6 } & Wasteland & $\begin{array}{l}\text { Built-up } \\
\text { land }\end{array}$ & Forest & Orchard & Cropland \\
\hline Wasteland & 4.26 & -0.27 & -40.31 & -8.51 & -9.02 \\
$\begin{array}{l}\text { Built-up } \\
\text { land }\end{array}$ & 10.83 & 2.221 & -28.14 & -8.38 & -3.64 \\
Forest & 81.56 & 107.64 & 85.69 & -5.42 & 80.43 \\
Orchard & 18.85 & 26.43 & 11.65 & 1.926 & 23.55 \\
Cropland & 23.60 & 18.93 & -11.93 & -1.62 & 8.19 \\
\hline
\end{tabular}

use transitions giving rise to increase in soil erosion are (1) forest to built-up land, (2) forest to wasteland, (3) forest to cropland, (4) orchard to built-up land, (5) cropland to wasteland, (6) orchard to cropland, (7) cropland to built-up land and (8) orchard to wasteland. Land use transitions showing positive effects on soil erosion include wasteland to forest, built-up land to forest, cropland to forest, wasteland to cropland, wasteland to orchard, as well as built-up land to orchard. Our results demonstrate that any land conversion to wasteland worsens soil erosion, whereas forestation and orchard development are the most powerful ways to help soil/water conservation and erosion control. Therefore, in the process of urban construction, massive forestation can effectively abate soil erosion in Guangdong.

Effect of land use changes on soil erosion at catchment scale

The spatial distribution of turn-into and turn-out of wasteland, built-up land, forest, orchard and cropland in 2009 compared to 2002 is presented in Fig. 5, where the red area represents the turn-into lands and the green area represents the turn-out ones. It includes five maps of land use changes: (1) the conversion of land into wasteland and that of wasteland to usable land in the first map (2) the other four maps show the areas converted to built-up, forest, orchard lands and cropland from other lands from 2002 to 2009, respectively. Note the trends of land use change in Fig. 5. Thus, for instance, wasteland and cropland in the centrally located Liuxi River Basin decreased significantly, whereas forest and orchard acreage remained unchanged and built-up land increased. For Beijiang Basin in the North, amounts of forested lands were converted into wasteland and built-up land. Orchards also showed a downward trend. The land use change of Dongjiang Basin shows transitions of wasteland to built-up area and cropland to orchard. Built-up land and orchard land in the Pearl River Delta witnessed a marked gain, while cropland and wasteland shrank heavily. Xijiang Basin underwent a transformation from orchards into cropland and forest. As far as Hanjiang Basin is concerned, extensive cropland and 

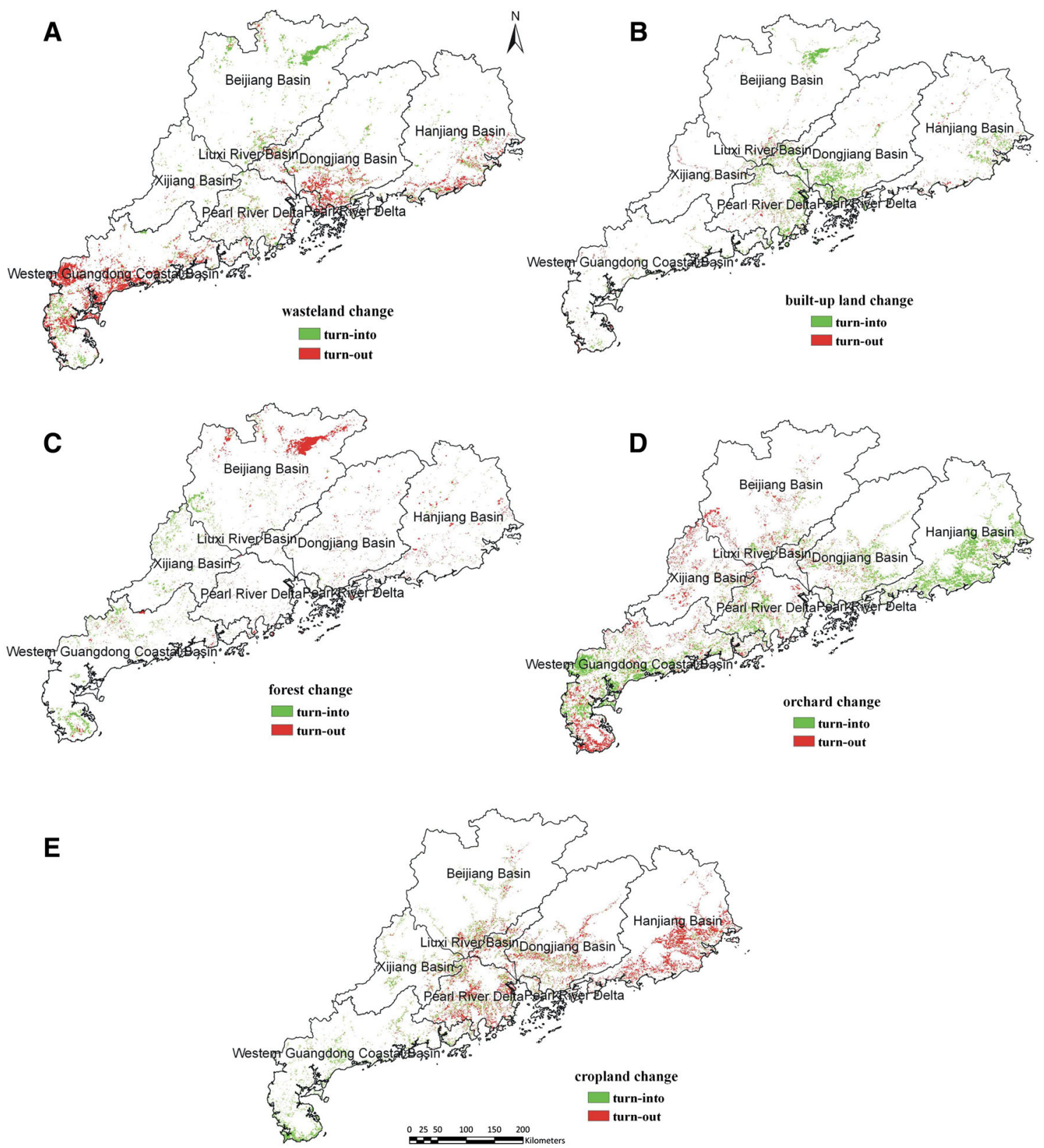

Fig. 5 The spatial distribution of turn-into and turn-out of land use in different catchments. There are five land use types: $\mathbf{a}$ wasteland $\mathbf{b}$ built-up land $\mathbf{c}$ forest, $\mathbf{d}$ orchard and $\mathbf{e}$ cropland

wasteland were converted into orchard and built-up land. The Western Guangdong Coastal Basin experienced a great reduction in wasteland and various increases in forest, orchard and cropland, and part of orchards have changed into forest and cropland.

Considering the effects of topography on soil erosion, we calculated and formed a slope map of Guangdong from DEM. It is indicated that the terrain in Guangdong is higher in the north and lower in the south. Mountains and hills occur primarily in the Beijiang, Dongjiang, Xijiang and Hanjiang Basins, and plains are concentrated in the Pearl River Delta, Liuxi River Basin and western Guangdong
Coastal Basin. The mean slope gradient of each catchment is in $6.64^{\circ}$ for Beijiang Basin, $5.42^{\circ}$ for Xijiang Basin, $4.88^{\circ}$ for Hanjiang Basin, $4.81^{\circ}$ for Dongjiang Basin, $2.8^{\circ}$ for Liuxi River Basin as well as $2.65^{\circ}$ for the Pearl River Delta and $2.44^{\circ}$ for western Guangdong Coastal Basin.

Then we calculated the average annual soil erosion amount of every catchment in 2002 and 2009 and their changes. The results show that except that erosion in Hanjiang Basin eased a little, other basins have undergone serious deteriorations in soil erosion during the study period, among which Beijiang Basin is the most severe catchment with increasing erosion from 18.46 to $52.35 \mathrm{t} /\left(\mathrm{hm}^{2 * a}\right)$. 
Fig. 6 Changing map of soil erosion from 2002 to 2009 in Guangdong, especially in Beijiang and Hanjiang basin
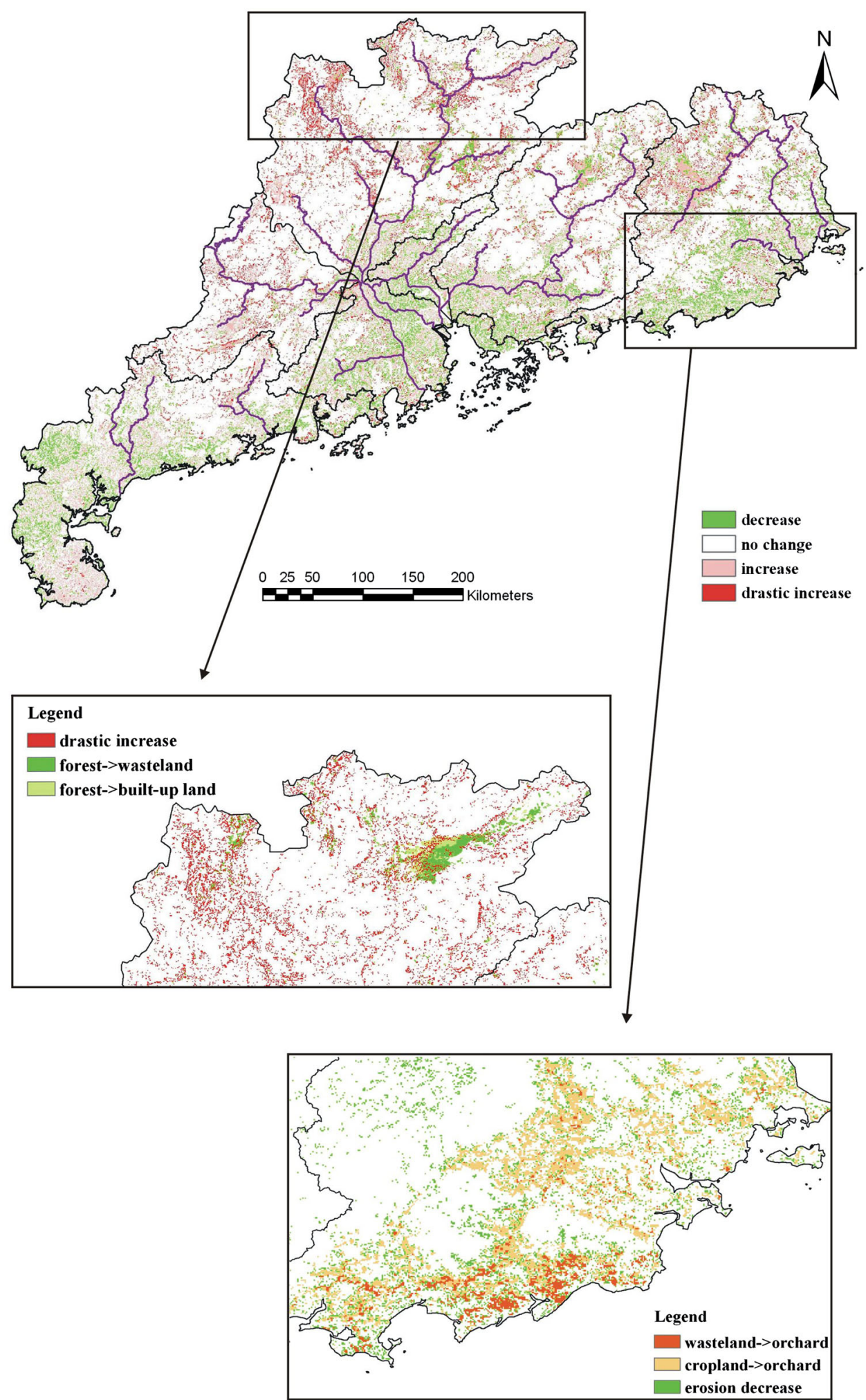

Although the Pearl River Delta area and Xijiang show small increasing in the mean annual soil erosion (7.54 and $15.19 \mathrm{t} /$ $\left(\mathrm{hm}^{2} * \mathrm{a}\right)$, respectively), they have changed into moderate erosion level from mild one together with Beijiang Basin. Meanwhile, Liuxi River Basin, Dongjiang Basin and
Western Guangdong Coastal Basin remained mild erosion during these years, increasing by $2.23,7.62$ and $6.36 \mathrm{t} /$ $\left(\mathrm{hm}^{2} * \mathrm{a}\right)$, respectively. Hanjiang Basin shows a slight alleviation with a decrease of $1.77 \mathrm{t} /\left(\mathrm{hm}^{2} * \mathrm{a}\right)$, but it still stays moderate erosion level. 
We also analyzed the changes of soil erosion during the study period using the Raster Calculator module in ArcGIS 9.2. To improve the images, we divided the changes into four categories. The categories and the corresponding thresholds are an erosion decrease with a change $<0 \mathrm{t} /$ $\left(\mathrm{hm}^{2} * \mathrm{a}\right)$, no change in erosion with a change $=0 \mathrm{t} /$ $\left(\mathrm{hm}^{2} * \mathrm{a}\right)$, an erosion increase with a change $<50 \mathrm{t} /\left(\mathrm{hm}^{2} * \mathrm{a}\right)$ and a dramatic erosion increase with change value $>50 \mathrm{t} /$ $\left(\mathrm{hm}^{2} * \mathrm{a}\right)$. This protocol produced a changing map of soil erosion from 2002 to 2009 in Guangdong (Fig. 6). The boundaries and main river channels were overlain on the map to fix the geography. This map shows that the areas with dramatic increase in soil erosion were located in the Beijiang and Xijiang Basin, whereas the areas with decreasing soil erosion were distributed along the coastal areas including the Pearl River Delta area, western Guangdong coastal area and the southern Hanjiang areas.

Comparing with the land use change maps, the most significant increase in soil erosion was in Beijiang Basin and corresponded to the areas of transition of forest and orchard to built-up land and wasteland. These areas are the main erosion zones in Guangdong and are harmful to regional soil and water conservation. In Xijiang Basin, tremendous reduction in orchards aggravated the soil erosion, and Fig. 6 also reflects that areas with severe soil erosion witnessed the reduction in orchards. In addition, there were many mountains and hills with higher slopes in these two basins, which show negative influences on soil erosion. Western Guangdong Coastal Basin experienced the conversion from wasteland into built-up area, and the main reason was that a variety of construction projects have been launched due to rapid urbanization and industrial development over the past decade. This land use conversion directly resulted in serious destruction of land and water resources around the city and severe soil erosion. However, in Hanjiang Basin, owing to considerable transitions of wasteland and cropland to orchard, the vegetation cover increased greatly; thus, the erosion was alleviated. In Fig. 6, two typical areas are selected to reflect the relationship of land use changes and soil erosion changes. One is in the northern Beijing Basin, where soil erosion shows spatial correlation with forest conversion to built-up and waste land, and the other one is in the southern Hanjiang Basin, where soil erosion is mainly related to the vegetation coverage increasing induced by to orchard conversions.

\section{Conclusion}

This study discussed the potential of using remote sensing and GIS to rapidly assess LUCC and its effects on soil erosion in Guangdong Province between 2002 and 2009.
Due to the fast economic development, the main land use change in Guangdong was significant decreases in wasteland and cropland, a slowdown in forest and enormous increases in built-up land and orchard. Meanwhile, the soil erosion in 2009 was much more severe than that of 2002. The average annual soil erosion amount was estimated about $21.86 \mathrm{t} /\left(\mathrm{hm}^{2} * \mathrm{a}\right)$ in 2009 comparing with $10.81 \mathrm{t} /$ $\left(\mathrm{hm}^{2} * \mathrm{a}\right)$ in 2002.

Statistical results show different land use types have great impacts on soil erosion. Taking 2009 as an example, the mean annual soil erosion amount of wasteland, cropland, built-up, forest and orchard are 60.19, 28.78, 26.75, 26.70 and $4.48 \mathrm{t} /\left(\mathrm{hm}^{2} * \mathrm{a}\right)$, respectively. Therefore, the management of soil erosion should begin with reasonable land use planning. Our results show the land use change induced by economic development and population growth also influence the soil erosion. Forestlands to built-up conversion promoted soil erosion increasing as high as $107.64 \mathrm{t} /\left(\mathrm{hm}^{2} * \mathrm{a}\right)$, while forest to wasteland conversion produced an increase in average annual soil erosion amount of $81.56 \mathrm{t} /\left(\mathrm{hm}^{2} * \mathrm{a}\right)$. Wasteland to forest, built-up land to forest as well as cropland to forest transitions showed positive effects on soil erosion.

We further analyzed the land use changes in seven catchments and the relationship between land use change and soil erosion. Beijiang Basin with an increase of $33.89 \mathrm{t} /\left(\mathrm{hm}^{2} * \mathrm{a}\right)$ underwent the most severe erosion mainly because of the drastic reduction in forest. The exploitation and destruction of forest owing to human activities including mining and deforesting affected the ability of soil consolidation and vegetation cover thus deepened the erosion. On the other hand, the improvement of soil erosion occurred in Hanjiang Basin, which was closely related to extensive expansion of orchards.

Our results suggested that forest and orchard can effectively increase the vegetation coverage and help control soil erosion, so vigorous afforestation and reasonable utilization of forest are useful means to control soil erosion. Since wastelands are the main land use category of soil erosion in Guangdong, strict regulations on mining and lumbering should be built by the government to strengthen the control of soil and water loss and lighten the destruction to water and soil environment. These management measures are particularly important for Beijiang Basin and Xijiang Basin. In addition, with rapid economic development and consequent large-scale urban construction, effective engineering measures for soil and water conservation, including drainage ditches, retaining walls and slope protection, as well as tree-planting measures, would be suggested for reducing soil erosion potentials.

Acknowledgments National Key Technologies R\&D Program in the 12th Five-year Plan of China (2012BAH32B03), NSFC 
(41171288) and Guangdong NSF (8151064004000013) are acknowledged for financial supports. Thanks to the National Aeronautics and Space Administration (NASA) for MODIS L1B data, and the China Meteorological Data Sharing Service System for sharing the meteorological products. Prof. Bernard de Jong of Utrecht University is greatly acknowledged for his help to improve the English of this manuscript. This is contribution No. IS-1687 from GIGCAS.

\section{References}

Bini C, Gemignani S, Zilocchi L (2006) Effects of different land use on soil erosion in the pre-alpine fringe (North-East Italy): ion budget and sediment yield. Sci Total Environ 369(1-3):433-446

Chen SL (2000) Study on the relationship between soil erosion and land use based on GIS. J Fujian Teach Univ (Nat Sci) 16(1): 106-109

Chen CY, Huang WL (2012) Land-use management and landslide characteristics analysis using GIS for community-based disaster mitigation. Environ Monitor Assess (on-line). doi:10.1007/ s10661-012-2855-y

Chen YH, Pan WB, Cai YB (2007) Quantitative study of soil erosion in watershed based on RS, GIS and RUSLE-A case study of the Jixi watershed in Fujian Province. J Geol Haz Environ Preserv 18(3):5-10

Erda W, Chang X, Jimmy RW, Cheng X (2006) Predicting soil erosion for alternative land uses. J Environ Qual 35(2):459-467

Fu BJ, Chen LD, Ma KM (1999) The effect of land use change on regional environment in the Yangjuangou catchment in the Loess Plateau of China. Acta Geographica Sinica 54(3):241-246

Fullen MA, Booth CA, Brandsma RT (2005) Long-term effects of grass ley set-aside on erosion rates and soil organic matter on sandy soils in east Shropshire, UK. Soil Tillage Res 89:122-128

Guangdong Soil census office (1993) Guangdong soil. Science Press

Hansen AJ, De Fries R, Turner W (2004) Land use change and diversity: a synthesis of rates and consequences during the period of satellite imagery. In: Gutman G, Justice C (eds) Land change science: observing, monitoring, and understanding trajectories of change on the earth's surface. Springer, New York, pp 277-299

Helena M, Lubos M, William MB (2001) Multiscale simulation of land use impact on soil erosion and deposition pattern. In: The 10th international soil conservation organization meeting, Purdue University, pp 1163-1169

Huang JL, Hong HS, Zhang LP, Du PF (2004) Study on predicting soil erosion in Jiulong River watershed based on GIS and USLE. J Soil Water Conserv 18(5):75-79

IGBP-IHDP (1995) Land-use and land-cover change science/research plan. IGBP report no. 35 and IHDP report no. 7, IGBP, Stockholm and IHDP, Geneva

Ito A (2007) Simulated impacts of climate and land-cover change on soil erosion and implication for the carbon cycle, 1901 to 2100. Geophys Res Lett 34:L09403. doi:10.1029/2007GL029342

Jordan G, van Rompaey A, Szilassi P, Csillag G, Mannaerts C, Woldai $T$ (2005) Historical land use changes and their impact on sediment fluxes in the Balaton basin (Hungary). Agric Ecosyst Environ 108:119-133

Li HX, Liu SZ, He XR, Fan JR (2004) Analysis of the relationship between soil erosion intensity and land use change in Suining city. Soil Water Conserv China 3:37-49

Liang Y, Shi XZ (1999) Soil erodiable K in east hilly fields of the southern Yangtze River. Res Soil Water Conserv 6(2):47-52

Liu P (2008) Analysis of the spatial variability of soil erosion amount in Guangdong Province based on GIS. South China Agricultural University, China
Liu BY, Nearing MA, Risse LM (1994) Slope gradient effects on soil loss for steep slopes. Trans ASAE 37:1835-1840

Lv XX, Shen RM (1992) A preliminary study on the values K of soil erosibility factor. J Soil Water Conserv 6(1):63-70

Ma CF, Ma JW, Buhe A (2001) Quantitative assessment of vegetation coverage factor in USLE model using remote sensing data. Bull Soil Water Conserv 21(4):6-9

Ma HL, Wang ZL, Zhou XW (2010) Estimation of soil loss based on RUSLE in Zengcheng, Guangdong Province. Yangtze River 41:90-93

Martha MB, Gerard G, van Anne D, Fabien Q, Dimitris C, Mark R (2008) The response of soil erosion and sediment export to landuse change in four areas of Europe: the importance of landscape pattern. Geomorphology 98(3-4):213-226

McCool DK, Foster GR, Mutchler CK, Meyer LD (1987) Revised slope steepness factor for the universal soil loss equation. Trans ASAE 30:1387-1396

Meng QH, Fu BJ, Yang LZ (2001) Effects of land use on soil erosion and nutrient loss in the three gorges reservoir area, China. Soil Use Manag 17:288-291

Pan MH, Wu YQ, Ren FP, Dong YF, Jiang Y (2010) Estimating of soil erosion in the Dongjiang River Basin based on USLE. J Nat Resour 25(12):2154-2164

Rey F (2003) Influence of vegetation distribution on sediment yield in forested marly gullies. Catena 50(2-4):549-562

Robert H (2000) Slope angle and slope length solutions for GIS. Cartography 29(1):1-8

Sharma A, Tiwari KN, Bhadoria PBS (2011) Effect of land use land cover change on soil erosion potential in an agricultural watershed. Environ Monitor Assess 173(1-4):789-801

Shi DM (1991) Soil erosion and its control in the granite region of Southern China. J Soil Water Conserv 5(3):61-72

Solaimani K, Modallaldoust S, Lotfi S (2009) Investigation of land use changes on soil erosion process using geographical information system. Int J Environ Sci Tech 6(3):415-424

Souchere V, King CH, Dubreuil N, Lecomte-Morel V, Le Bissonnais Y, Chalat M (2003) Grassland and crop trends: role of the European Union Common Agricultural Policy and consequence for runoff and soil erosion. Environ Sci Policy 6:7-16

Statistics Bureau of Guangdong Province, National Bureau of Statistics Guangdong Survey Organization (2003 and 2010) Guangdong Statistical Yearbook. China Statistics Press

Stoate C, Boatman ND, Borralho RJ, Carvalho CR, De Snoo GR, Eden P (2001) Ecological impacts of arable intensification in Europe. J Environ Manag 63:337-365

Szilassi P, Jordan G, Van Rompaey A, Csillag G (2006) Impacts of historical land use changes on erosion and agricultural soil properties in the Kali Basin at Lake Balaton, Hungary. Catena 68(2-3):96-108

Tang GA, Yang X (2006) Experimental tutorial for GIS spatial analysis using ARCGIS. Science Press

Wang SY, Liu JY, Zhang ZX, Zhang ZK (2001) Study on spatialtemporal feature of land use and land cover under different background of soil erosion. J Soil Water Conserv 15(3):48-51

Wischmeier WH, Johnson CB, Cross BV (1971) A soil erodibility nomograph farmland and construction sites. J Soil Water Conserv 26(5):189-193

Yu QG (1996) Land use and soil erosion study by use of remote sensing information in Hongtagou watershed on Rolling Loess Plateau. J Soil Water Conserv 2(2):24-31

Zhang LM (2005) Soil erodibility and its relative factors of different soil types in subtropical China. South China University of Tropical Agriculture, China

Zhou FJ, Chen MH, Lin FX, Huang YH, Lu CL (1995) The rainfall erosivity index in Fujian Province. J Soil Water Conserv 9(1):13-18 
Zhu LA, Wang JZ, Zhuo MN, Zhang HH (2003) Regional disparity of soil and water loss in Guangdong Province. Bull Soil Water Conserv 23(6):36-38
Zou YR, Zhang ZX, Zhou QB, Liu B, Wang BC (2002) Analysis of the relationship between soil erosion and land use based on GIS. Res Soil Water Conserv 9(1):67-69 